\title{
Adult Follicular Conjunctivitis and Neonatal Ophthalmia in a Liverpool Eye Hospital, 1980-1984
}

\author{
S. P. HARDING,${ }^{*}$ H. MALLINSON,$\dagger$ J. L. S. SMITH, $\ddagger$ and L. G. CLEARKIN \\ Liverpool
}

\begin{abstract}
Summary
In the five year period between 1980 and 1984, 2146 adults and 172 neonates suffering from acute conjunctivitis underwent laboratory investigation for Chlamydia trachomatis (CT), Adenoviruses (AV), Herpes Simplex Virus (HSV) and pathogenic bacteria. Epidemiology and clinical features are presented and discussed.

CT was detected in 29 per cent of neonates with conjunctivitis. 5.6 per cent of adults and older children investigated for follicular conjunctivitis were CT positive. There was a significant female preponderance among CT positive neonates of 1.9:1 $(\mathrm{p}<0.02) .91$ per cent of neonates and 62 per cent of adults in whom CT was detected were receiving some sort of treatment.

Serotypes 7, 3, 10, 4 and 8 were responsible in decreasing order of frequency for 96 per cent of AV infections. Serotype 7 was seen for the first time in an adult age distribution.

HSV was isolated in 1.3 per cent of cases in the absence of typical lid or corneal lesions. Viral infection was not detected in any neonate.

Bacterial infection was a more likely cause than CT in neonates if infection had persisted longer than 5 weeks $(\mathrm{p} \ll 0.001)$. Neonates with Staph aureus infection tended to present earlier in the course of disease than those with Haemophilus sp or Pneumococcus $(\mathrm{p}<0.05)$.
\end{abstract}

Acute conjunctivitis is a common reason for attendance at an ophthalmic accident and emergency department (AED). In adults the presence of follicles in the palpebral conjunctiva and/or keratitis alerts the ophthalmologist to consider as causative organisms Chlamydia trachomatis (CT), Adenovirus (AV) and less frequently Herpes simplex virus
(HSV). In the neonate presenting with conjunctivitis the detection of CT is often the first sign of infection in the parents. ${ }^{1}$ It has been the policy at St Paul's Eye Hospital, Liverpool to investigate patients with conjunctivitis by a combination of chlamydial, viral and bacterial culture supported by conjunctival cytology in the majority of cases. This report presents the

\footnotetext{
* Lecturer in Ophthalmology, University of Liverpool, Honorary Senior Registrar, St Paul's Eye Hospital, Old Hall Street, Liverpool, L3 9PF.

$\dagger$ Principal Microbiologist, Public Health Laboratory Service, Fazakerley Hospital, Longmoor Lane, Liverpool L9 7AL.

$\ddagger$ Consultant Pathologist, St Paul’s Eye Hospital, Old Hall Street, Liverpool, L3 9PF.

$\S$ Senior Registrar in Ophthalmology, St Paul's Eye Hospital, Liverpool, L3 9PF.
}

Correspondence to: Mr. S. P. Harding, St Paul's Eye Hospital, Old Hall Street, Liverpool L3 9PF. 
results of a five year study of the epidemiology and clinical features of CT, AV and HSV ocular infections in patients attending the hospital.

\section{Patients and Methods}

The laboratory records of all patients investigated for CT and AV at St Paul's Eye Hospital, Liverpool between January 1980 and December 1984 inclusive were examined. These were divided into two groups: infants with conjunctivitis whose onset was within 28 days of birth; adults and older children in whom a chlamydial aetiology was clinically suspected. The case records of all patients diagnosed as suffering from CT conjunctivitis were sought and clinical features and previous treatment were noted.

During epidemics of AV, in order not to overload the laboratory services, clinically typical cases of AV were not investigated routinely. Investigations were only performed where clinical diagnosis was in doubt, and also on a proportion of typical cases to characterise the epidemic serotype.

Routine culture for HSV infection is performed at another laboratory and so HSV isolates in this series are incidental findings in patients presenting with follicular conjunctivitis without typical lid or corneal signs.

Chlamydial Culture: Specimens collected from the lower conjunctival fornix were transported to the Public Health Laboratory (PHL), Fazakerley in $2.5 \mathrm{ml}$ of medium consisting of Wellcome medium 199 with 0.11 per cent sodium bicarbonate, 10 per cent fetal bovine serum 5 per cent sorbitol, 0.5 per cent glucose and 100 units/ml each of vancomycin, streptomycin and mycostatin. Specimens were inoculated into idoxuridine treated McCoy cell cultures as previously described. ${ }^{2}$ After 72 hours incubation McCoy cell monolayers were stained with Giemsa and observed by dark-ground microscopy.

Viral Culture: Conjunctival swab specimens received for chlamydial isolation were also inoculated into $\mathrm{HEp}^{2}$, Human Amnion and Baboon Kidney cell monolayer cultures, a range most likely to detect ocular virus strains, and were examined during a three week incubation period for the development of viral cytopathic effects. Isolated viruses were identified by neutralisation tests.

Bacterial Culture: Conjunctival swabs were transported as dry swabs to the laboratory in the same building and plated out onto blood agar and chocolate agar usually immediately or at the latest on the next working day. Scanty growths and commensal organisms were ignored.

Conjunctival Cytology: Scrapings from the lower conjunctival fornix were smeared onto glass slides and examined for inclusions and general cytology using a sequence Azure-Eosin stain (DiffKwik, MercDade) by a single observer (JLSS).

\section{Results}

During the study period 2,318 patients were investigated. They comprised 2,146 adults and older children and 172 neonates. Annual numbers of patients investigated increased dramatically from 148 in 1980 to 841 in 1984 reflecting an increased awareness of the importance of accurate laboratory diagnosis.

\section{Chlamydia}

CT conjunctivitis was diagnosed in 29 per cent (50 of 172) neonates and 5.6 per cent (120 of 2146) adults and older children. Thirty-three of the 50 neonatal cases were female giving a female to male ratio of 1.9:1. When compared with the annual local newborn sex distribution $(33,735$ males, 31,650 females) this difference achieved a high level of significance $\left(\chi^{2}=6.041, \mathrm{p}<0.02\right)$.

Numbers detected each year were similar but due to the large increase in investigations isolation rates fell from 11.6 per cent in 1981 to 2.9 per cent in 1984 . There was no significant sex predominance in adults and older children $\left(\chi^{2}=1.127, \mathrm{p}>0.1\right)$.

Age:

Figure 1 shows the ages at onset of symptoms in neonates: mean was 5.4 days $(\mathrm{SD}=3.59)$; range was $1-14$ days.

Figure 2 shows the age distribution in adults and older children: mean was 23.9 years $(\mathrm{SD}=8.64)$, range was $2-62$ years. Four children, ages 2, 6, 6 and 7 were seen. Seventyfour per cent (89 of 120) patients were between 15 and 29 years old and 89 per cent (107 of 120) were between 15 and 44. Detection rates rose from 5.6 per cent overall to 7.3 per cent for 15 to 44 years and 9.3 per cent for 15 to 29 years.

Sixty-nine per cent ( 22 of 32 ) cases in the 15 to 19 year age group were female, though this difference did not achieve statistical significance when compared with the local sex distribution for that age group $\left(\chi^{2}=0.982 ; p>0.1\right)$. Sex distribution was about equal between 20 and 24 years (19 females, 22 males). Ninety 


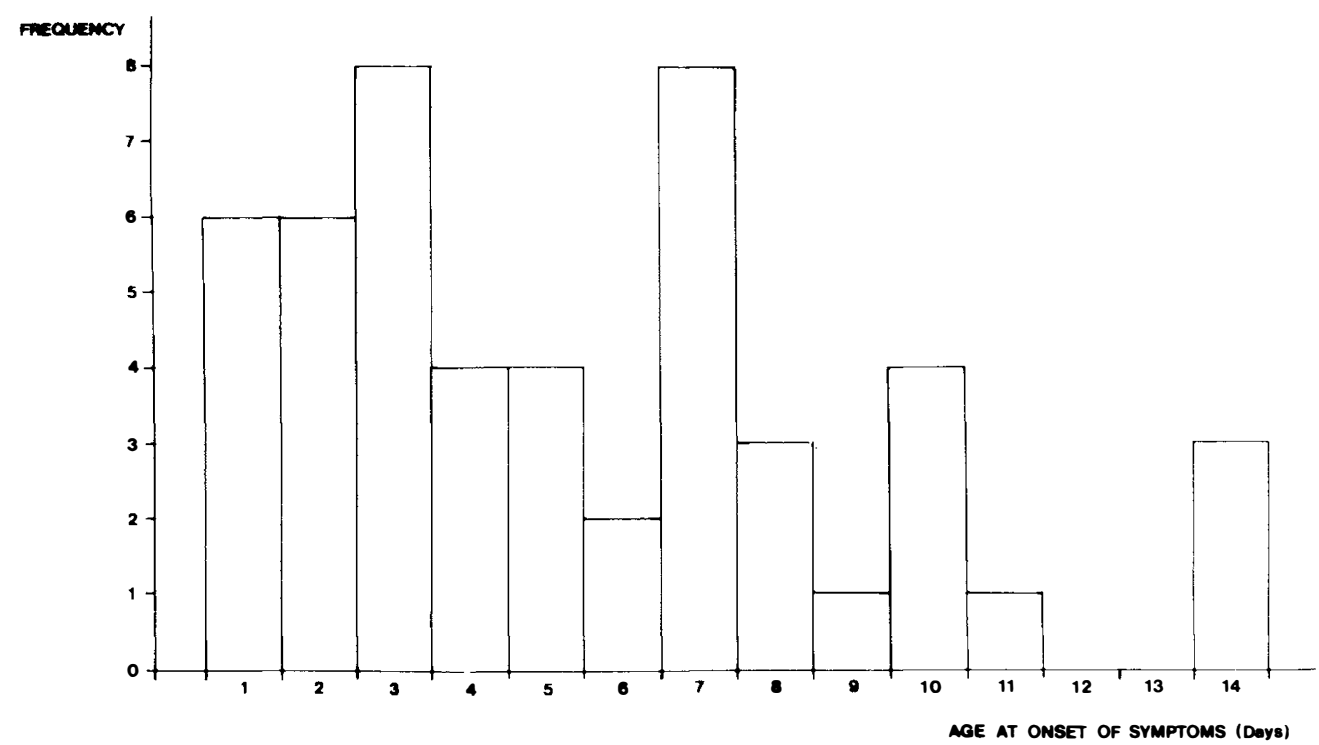

Fig. 1. Age at onset of 50 neonates with chlamydial conjunctivitis.

per cent ( 33 of 36 cases) between 25 and 39 days to 5 weeks; $\mathrm{SD}=6.57$ days). For adults years were male; when compared with catch- and older children mean delay was 14.2 days ment population statistics this was significant (range 1 day to 6 months; $\mathrm{SD}=22.75$ days). $\left(\chi^{2}=4.992 ; \mathrm{p}<0.05\right)$.

There was no significant difference between mean delay in neonates and adults

Duration of Symptoms:

In neonates there was a mean delay of 10.4 adult patients had symptoms for a period of days between onset and presentation (range 3 four weeks or less.

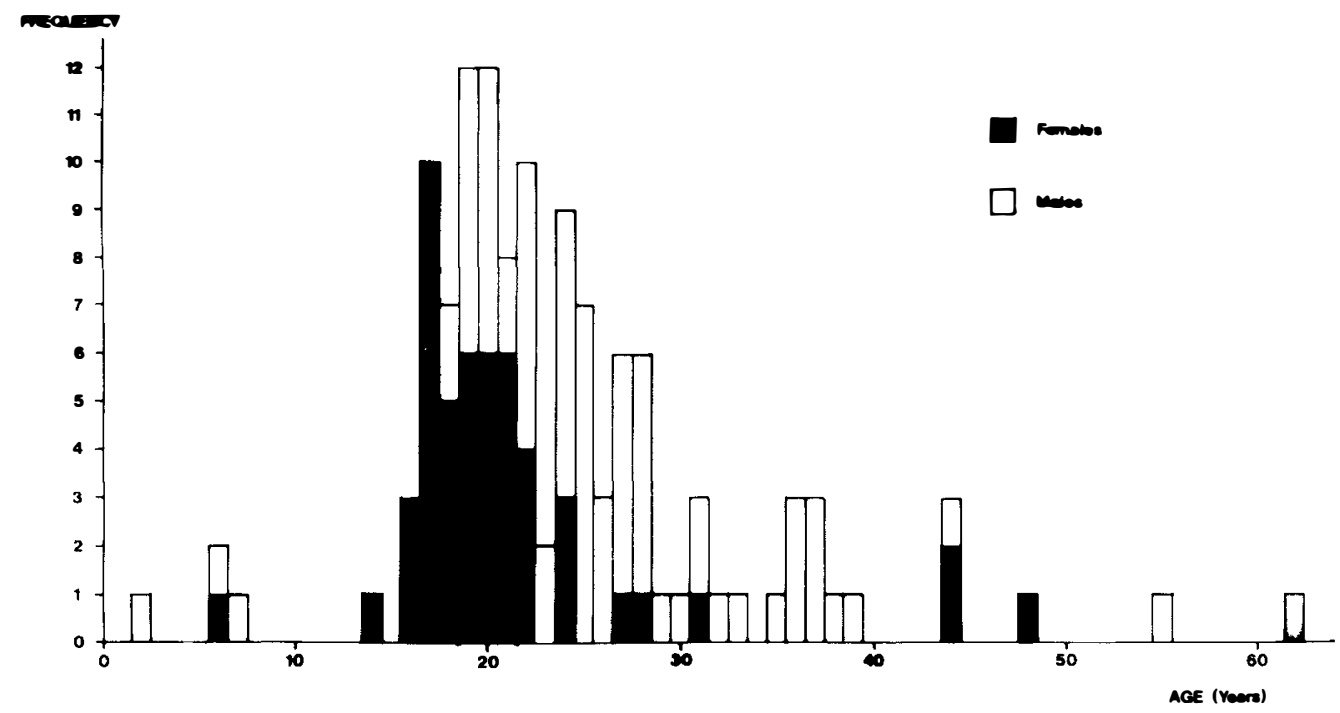

Fig. 2. Ages of 120 adults with chlamydial conjunctivitis. 
The clinical records of $156 \mathrm{CT}$ cases (42 neonates, 114 adults) were available for further analysis.

\section{Clinical Features:}

In neonates 62 per cent ( 23 of 37) cases were unilateral. All eyes were reported as 'sticky' and in addition four cases were haemorrhagic. All cases showed conjuctival injection and no iritis, pseudomembranes, preauricular lymphadenopathy or corneal involvement was recorded.

In adults 81 per cent ( 82 of 106$)$ cases were unilateral. 73 per cent ( 51 of 70 ) were sticky while 2 were haemorrhagic. All recorded cases had conjunctival injection and follicles. Two cases with mild iritis and one pseudomembranous conjunctivitis were seen. Corneal involvement was common occurring in 37 per cent ( 28 of 75 ): 23 showed fine epithelial keratitis; five marginal infiltrates; one coarse epithelial keratitis and two multiple subepithelial opacities.

\section{Previous Treatment:}

Whether treatment had or had not been prescribed in the week prior to investigation was noted on 121 records (34 neonates, 87 adults). Eighty-six patients ( 71 per cent) had received previous treatment and 14 of those with multiple drugs. Thirty-one neonates (91 per cent) had received treatment, twenty-one of these with chloramphenicol. Fifty-three $(62 \%)$ of adults had previous treatment. Chloramphenicol did not appear to interfere with diagnosis by McCoy cell culture. Forty-six CT positive patients received chloramphenicol prior to diagnosis of which 32 (70 per cent) were culture positive. Of thirty who received no previous treatment 22 (73 per cent) were culture positive.

\section{Adenovirus}

2,123 patients had viral culture (166 neonates, 1957 adults). No viruses were identified in neonates. In adults and older children $175(9.0$ per cent) AV infections were diagnosed. One hundred and six of the 175 isolates were from males giving a male to female sex ratio of 1.5:1. Ages of adults and older children with AV infections showed near Gaussian distribution (Fig. 3): mean 30 years; SD 13.9 years; range 2 months -77 years. During two short periods in 1983 and 1984 adenovirus serotyping was suspended due to technical difficulties so that 34 cases were not typed. The result of serotyping the remaining $141 \mathrm{AV}$ isolates is shown in Table I.

A number of epidemics occurred during the study period. The two largest were caused by types 8 and 10; the former occurred between October 1982 and January 1983, and the latter between August 1984 and early 1985. Both resulted in several doctors and nurses becoming infected with subsequent suspension of routine admissions. Type 4 showed an even spread throughout the first few years with a decline in 1984. Type 7 showed a marked increase in 1983-84. Two epidemics of lesser magnitude were caused by type 3 in MayNovember 1981 and April-August 1984. Types 1, 2, 5 and 11 were sporadic. Seasonal variations were apparent for the commoner serotypes with 3 and 7 less common in winter months but 8 and 10 only occurring in winter. Type 4 showed an even spread.

Duration of symptoms at presentation and investigation is shown in Figure 4. Ninety-five per cent (163 of 171 known durations) were diagnosed within 15 days of onset. Eighty-two per cent (143 of 174) attended within 7 days of onset of symptoms indicating the acute nature of the disease. All serotypes conformed to the pattern in Figure 4.

\section{Herpes Simplex Virus}

HSV was isolated as an incidental finding in 27 patients (1.3 per cent). Mean age was 25.5 years with a range of 9 months to 60 years. HSV was not detected in any neonate. Pattern of age distribution was similar to AV with 63 per cent occurring in the 10-30 year age group and only 2 children, aged 9 and 18 months. Maximum symptom duration at presentation and investigation was 8 days.

\section{Other viruses}

Three ECHO virus infections were seen, one each of serotypes 3,7 and 11 , indicating a sporadic incidence. Clinically they were indistinguishable from AV infections. One case of molluscum contagiosum was diagnosed in the laboratory from a lower conjunctival fornix swab. On later re-examination a molluscum 


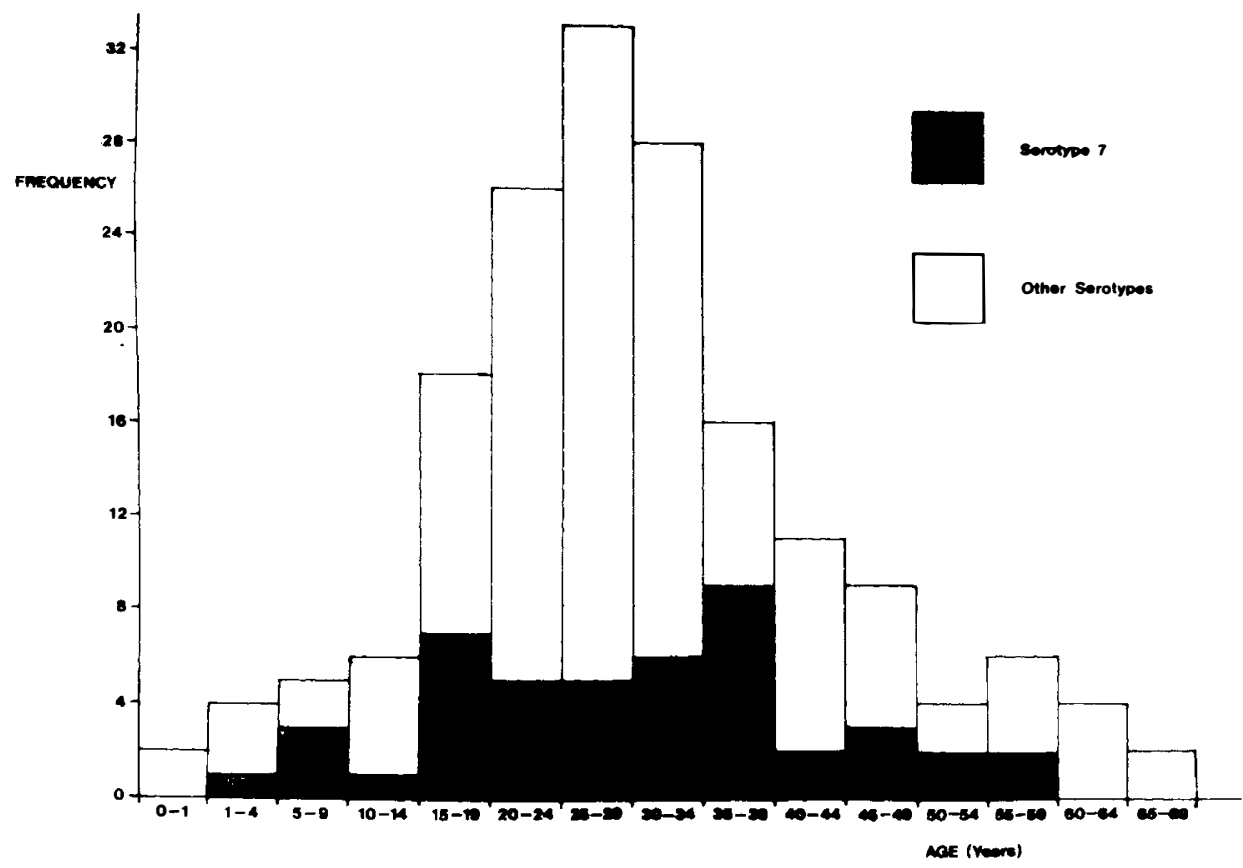

Fig. 3. Ages of patients with adenovirus infections for the overall group and for serotype 7 .

which had been previously missed was noted on the lid margin.

\section{Associated Bacteria}

Forty-seven of 50 neonates with CT conjunctivitis had bacteriology performed and in

Table I. Frequency of HSV and various serotypes of AV isolated 1980-84.

\begin{tabular}{lcccccc}
\hline & 1980 & 1981 & 1982 & 1983 & 1984 & Total \\
\hline HSV & 1 & 2 & 2 & 8 & 14 & 27 \\
\hline AV Serotypes & & & & & & \\
1 & 1 & 1 & & 1 & 3 \\
2 & & 1 & & & & 1 \\
3 & & 8 & 1 & 4 & 15 & 28 \\
4 & 5 & 8 & 3 & 5 & 1 & 22 \\
5 & 2 & 3 & 4 & 16 & 19 & 44 \\
7 & & & 15 & 1 & 1 & 17 \\
8 & & 2 & 1 & 2 & 19 & 24 \\
10 & & & & 1 & & 1 \\
11 & & & & 10 & 24 & 34 \\
Unspecified & & 23 & 25 & 39 & 81 & 175 \\
\hline & 7 & & & & & \\
\hline
\end{tabular}

5 (11 per cent) a pathogenic bacteria was isolated (Staph. aureus 2, Proteus mirabilis 1, Candida albicans $1, \beta$-haemolytic Strep. 1). By contrast of $48 \mathrm{CT}$ negative neonates who had bacteriology performed 20 ( 42 per cent) had a pathogenic infection with four being mixed. Commonest was Pneumococcus (8) followed by Haemophilus sp. (7), Staph. aureus (7), B. Catarrhalis (1) and $\beta$-haemolytic Strep. (1).

Symptom duration at presentation in 105 infants under 12 months of age who had all investigations performed is compared with the infecting organism in Table II. If symptoms had persisted longer than 5 weeks before presentation there was a highly significant likelihood that infection was bacterial $(\mathrm{p} \ll 0.001)$. Patients with Staph. aureus infections tended to present earlier in the course of the disease than those with Haemophilus sp. or Pneumococcus (two sample t test, $\mathrm{p}<0.05$ ) with means of 23 days for Staph. aureus and 78 days for Haemophilus sp. and Pneumococcus infections.

Pathogenic bacteria were isolated from 2 adults with CT conjunctivitis (Pneumococcus 


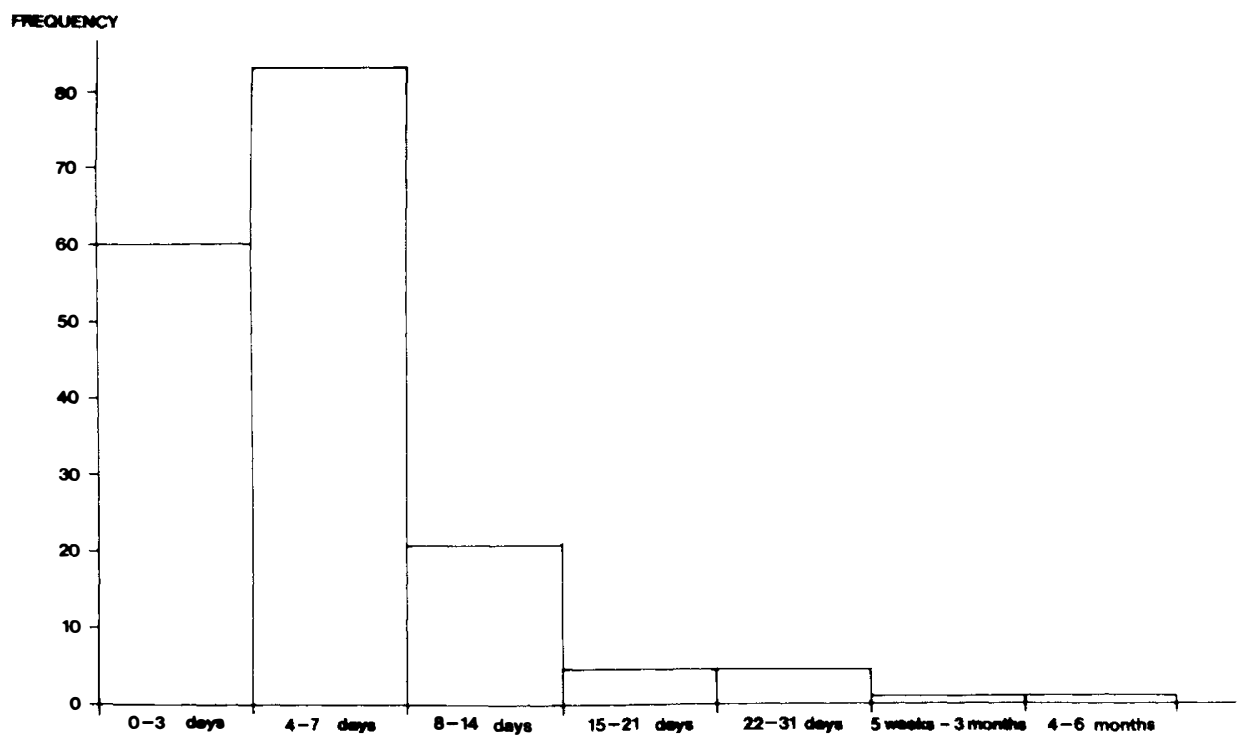

Fig. 4. Duration of symptoms at presentation and investigation in 174 subsequent culture proven adenovirus infections.

1, Staph. Aureus 1) and from 2 with AV infections (Staph. aureus 1, B. catarrhalis 1).

\section{Discussion \\ Chlamydia}

In this study CT was isolated in 29 per cent of neonates with conjunctivitis presenting to an ophthalmic AED much in keeping with recent reports. ${ }^{3.4}$ Rees et al. ${ }^{5}$ in Liverpool found CT in 32 per cent of babies, mostly neonates, and mostly referred after failed first line treatment. 38 per cent of 199 neonates with sticky eyes examined in 1979 in Glasgow had CT. ${ }^{6}$ In

Table II. Symptom duration related to causative organism for 105 infants presenting with conjunctivitis who had chlamydia and bacterial investigations.

\begin{tabular}{|c|c|c|}
\hline & $\begin{array}{c}\text { Symptom } \\
\leqslant 5 / 52 \\
(n=77)\end{array}$ & $\begin{array}{l}\text { ration } \\
\qquad 5 / 52 \\
(n=28)\end{array}$ \\
\hline Chlamydia trachomatis & 47 & 0 \\
\hline All pathogenic bacteria & 23 & 14 \\
\hline Pneumococcus & 5 & 6 \\
\hline Staph. aureus & 8 & 2 \\
\hline Haemophilus sp. & 3 & 6 \\
\hline
\end{tabular}

Harrow however, Prentice et al. ${ }^{7}$ found a surprising absence of CT in 104 neonates developing conjunctivitis in a maternity unit.

The incidence of ophthalmia neonatorum has been reported as 8.2 per cent and 12 per cent in two recent prospective series from British maternity units $;^{7,8}$ these would include many mild cases that would not normally attend an eye hospital. The unusually high female to male preponderance of $2: 1$ in our study has not been previously reported to the best of our knowledge and is of great interest. Low lysozyme ${ }^{9}$ and Ig A levels ${ }^{8}$ occur in some neonates depending on gestational age and birthweight but no work has been performed to detect a sex difference in these factors.

Classically the age at onset of symptoms has been stated as between 5 and 12 days. ${ }^{10-12}$ Rees et al. ${ }^{5}$ found a wider spread of 3 to 13 days. Twenty-four neonates in this study (48 per cent) were symptomatic before 5 days of age and 12 ( 28 per cent) in the first two days and this is more in keeping with the findings of Freedman et al. ${ }^{13}$ These early cases in our series are more frequent than in previous reports. We do not feel therefore that too 
much reliance should be placed upon age at onset and that all neonates with conjunctivitis should have CT investigations.

Nearly all neonates (91 per cent) and the majority of adults (62 per cent) in whom CT was detected in our ophthalmic AED had had some sort of prior treatment (91 per cent) just over half with chloramphenicol and 6 with multiple therapy. Chloramphenicol delays onset and diminishes signs sufficiently to impair diagnosis without clearing infection. ${ }^{14}$ Such frequent use of chloramphenicol as a blind therapy is not to be recommended. CT has nonetheless been readily detected in our mainly treated group of patients including 21 neonates who received chloramphenicol. It is clear that neonates who are on antibiotics at presentation should be fully investigated at the first visit rather than risk delaying detection by waiting for a one or two week period without treatment.

Clinical signs in our neonates with CT are consistent with previous reports; pseudomembranes and corneal involvement have occasionally also been reported. ${ }^{10,15}$ Follicles are not seen under 3 weeks of age and thereafter remain uncommon ${ }^{13}$-none were recorded in our cases.

Pathogenic bacterial infection was uncommon in CT positive neonates in this series. No Gonococcus was seen although its co-existence with CT has often been reported..$^{5.11}$

In patients with prolonged symptoms (more than 5 weeks) only bacteria were grown. It appears therefore that the longer symptoms persist before presentation of ophthalmia neonatorum the less likely $\mathrm{CT}$ is to be detected. This is in direct contradiction to the generally held view that persistent symptoms tend to suggest CT rather than bacteria which have in the past been considered self limiting. Furthermore for the adult population our results show that there is little likelihood of detecting CT four weeks or longer after onset of symptoms.

Two possibilities suggest themselves. Firstly CT conjunctivitis may be a self limiting disease with eradication of organisms by host defences. Secondly a chronic low-grade infection may develop resulting in presently available tests becoming insufficiently sensitive to detect the low number of remaining organ- isms and this has been supported by the findings of Rowe et al. ${ }^{4}$ It is also possible that pernasal swabs or serology might detect a number of cases in any such chronic group.

This study shows that bacterial infections of shorter duration at presentation are likely to be Staph. aureus while longer durations occur with Haemophilus sp. and Pneumococcus. and this supports similar findings by Mallinson et al. ${ }^{16}$ Indeed, 14 of 19 cases of Haemophilus and Pneumococcus developed within the neonatal period and persisted for several months. It seems that Haemophilus and Pneumococcus infections are often less florid and therefore investigation of affected neonates is frequently delayed.

In this series the isolation rate of Staph. aureus was similar to that of Pneumococcus and Haemophilus sp., in contrast to previous reports from two maternity units ${ }^{8,16}$ and one well child clinic ${ }^{4}$ in which Staph. aureus was considerably more common. This is probably due to an additional group of older babies who present only to an ophthalmic department.

No viruses were detected in 166 neonates investigated. This has not been previously commented upon in connection with $\mathrm{AV}$ and is of interest. ${ }^{17-21}$ The youngest infant with $\mathrm{AV}$ in our series was aged 2 months at time of onset and thus it seems that investigation for viruses in that neonatal period is unprofitable. It is probable that transplacentally acquired immunity protects neonates from AV conjunctivitis.

Overall 5.6 per cent of our 2,146 adults had CT conjunctivitis. This compares with similar findings of $2.8-18$ per cent ${ }^{3,22.23}$ in populations attending other eye units as does the increased frequency in young adults. ${ }^{23}$ Because only those clinically suspected of CT were investigated and a proportion were missed during AV epidemics we are not able to comment on the incidence in the local population. The difficulty of obtaining this information is illustrated by Tullo et al. ${ }^{24}$ whose estimate of the incidence in the general population in Bristol of $1: 100,000$ was based upon only 13 cases attending an eye hospital in a two year period.

The finding of CT in four children suggests that non-sexual transfer is a definite route of spread as Freedman et al. pointed out. ${ }^{13}$ The predominance of females between 15 and 19 
years and males between 25 and 39 years would seem to indicate age differences in sexual activity.

One can identify four distinct groups of CT infection. Neonates contract infection at birth becoming symptomatic within 14 days of birth, while young adults between 15 and 40 have the peak incidence of infection when sexual activity is most pronounced. In contrast young children can acquire CT by nonsexual transfer from a parent while older adults, as Freedman et al. ${ }^{13}$ pointed out, tend to be grandparents of affected neonates. When investigating the family of a neonate with CT conjunctivitis the clinician ideally should check all symptomatic relatives and close contacts rather than only the parents.

\section{Adenoviral Infection}

AV serotypes seen in the 5 years coincide in general with two previous studies in London by Darougar et al. The first reported serotypes of AV from 1973 to $1978^{17}$ and the second reported an unspecified 12 month period in the early 1980s (probably 1981). ${ }^{18}$

In a worldwide survey of 25,000 reports of AV infections to WHO between 1967 and 1976 Schmitz et al ${ }^{19}$ found absolute frequencies, in decreasing order, of serotypes $2,1,7$, $3,5,6,4$ and 8 with other serotypes in only small numbers; 3.5 per cent of these were ocular. Ninety-six per cent of isolated cases in Liverpool were due to types 7, 3, 10, 4 and 8 in decreasing order of frequency. Excluding types 2, 1, 5 and 6 which caused non-ocular clinical syndromes our order of frequency was identical to those in the worldwide survey except for the occurrence of serotype 10 in the final year of our study.

Type 7 was infrequently seen in the United Kingdom until 1971 when a nationwide epidemic occurred, ${ }^{20}$ mainly in children (50 per cent aged 6 or under) with several cases of meningitis and encephalitis. It appeared to represent a change in pathogenicity with rapid spread through a large pool of young susceptibles. Schmitz et al. ${ }^{19}$ found a similar peak of type 7 on a worldwide basis in 1973 and 1974 causing ocular infection and fever with some fatalities in children; he saw mainly respiratory infections in adults. The rise in incidence in 1983-84 in Liverpool indicates a further epidemic cycle but this time in an adult age distribution more typical of other serotypes (Fig. 3). The implication, therefore, is that a change to greater pathogenicity at first affects children while later epidemics show a more typical age pattern as community levels of immunity rise.

Type 3 appears to present in Liverpool as community based epidemics of fairly short duration. Type 4 was fairly common in London showing a steady rise over four years to $1978^{17}$ with an apparent fall by $1981 . .^{18} \mathrm{In}$ Liverpool, type 4 showed a steady incidence until a fall in 1984.

Types 8 and 10 presented as hospital based epidemics; the first, which has been reported elsewhere, ${ }^{21}$ reached large proportions in 1982-3 due to a failure in early recognition, but was contained once adequate measures were initiated. A high level of monitoring and awareness is needed and affected members of staff must be kept off work until resolution. Standards of hygiene must be maintained at all times to reduce the extent and frequency of these outbreaks. Unlike in London in the 1970 s, ${ }^{17}$ we did not see type 10 , except sporadically, until the 1984 epidemic. We note that in the later paper from the same group in the early $1980 \mathrm{~s}^{18}$ there was a similar absence of type 10.

A predilection for males was seen with types 7, 3 and 10 but not with types 4 and 8 . Schmitz et al. ${ }^{19}$ found significant male predilections for the same serotypes and in addition type 4 . The collection of swabs after 15 days from the onset of symptoms is unlikely to isolate $\mathrm{AV}$ and therefore is of little value.

\section{Herpes Simplex Virus Infection}

Darougar et al., ${ }^{25}$ between 1973 and 1980, reviewed 108 cases of HSV ocular infection of which 8 ( 7 per cent) presented as acute follicular conjunctivitis in the absence of corneal or lid signs. HSV was isolated in 27 of our cases (1.4 per cent); though uncommon HSV can present as an acute follicular conjunctivitis or keratoconjunctivitis clinically indistinguishable from other more likely causes.

Wishart et al. ${ }^{22}$ in a small series of 140 consecutive cases of acute conjunctivitis found a 
remarkable 21 per cent due to HSV ocular infection, however their diagnostic criteria in most cases relied on a single estimate of $\mathrm{IgG}$ levels in blood or tears. In only 8 of their cases was HSV culture positive of which 4 ( 3 per cent) had no typical lid or corneal signs, a figure that is similar to our isolation rate. Epidemiology in our cases of HSV was similar to previous reports ${ }^{25}$ with only 2 cases under 5 years old and wide range of ages. Its absence in any baby under nine months old suggests that HSV is not a major problem in this age group though its isolation has been reported as an infrequent event. ${ }^{26}$

\section{Conclusions}

This study emphasises that all cases of ophthalmia neonatorum should be investigated for both CT and other bacteria but that viral investigations are of little value. For adults and older children we think it is impractical to investigate all cases of conjunctivitis for CT and viral infection. However it is reasonable to test for $\mathrm{CT}$ in all cases with a follicular reaction and other cases only when $\mathrm{CT}$ is suspected on clinical grounds or is present in the family; the aim must be to diagnose $\mathrm{CT}$ whenever possible as a preventive public health measure.

Viral investigations with rapid reporting are important in allowing early recognition and characterisation of epidemics of $\mathrm{AV}$ and should be carried out on all clinically typical cases with an appropriate reduction during major outbreaks. Co-operation between clinical and laboratory services will reduce the extent of epidemics which can pose a real threat to the running of an ophthalmic unit.

We thank the Consultant staff at St Pauls Eye Hospital for allowing us to study their patients, Mrs. D. Kinsella and Mrs. E. S. Mallinson for secretarial work and $\mathrm{Mr}$. C. Mody for photographic assistance.

\section{References}

${ }^{1}$ Dunlop EMC: Chlamydial genital infection and its complications. Br J Hosp Med 1983, i: 6-11.

${ }^{2}$ Mallinson H, Sikotra S, Arya OP: A cultural method for large scale screening for Chlamydia trachomatis genital infection. J Clin Pathol 1981, 34: 118-24.

${ }^{3}$ Viswalingham ND, Wishart MS, Woodland RM:
Adult Chlamydial Ophthalmia (Paratrachoma) Br Med Bull 1983, 39: 123-7.

${ }^{4}$ Rowe DS, Aicardi EZ, Dawson CR, Schacter J: Purulent Ocular Discharge in Neonates: Significance of Chlamydia trachomatis. Pediatrics 1979, 63: 628-30.

${ }^{5}$ Rees E, Tait IA, Hobson D, Byng RE, Johnson FWA: Neonatal conjunctivitis caused by Neisseria Gonorrhoeae and Chlamydia trachomatis. Br J Vener Dis 1977, 53: 173-9.

${ }^{6}$ Summerville RG, Lunan CB. Wolfsberger J: Neonatal chlamydial eye infection in the Eastern District of Glasgow in 1979. Communicable Diseases (Scotland), 1980, 8: vii.

7 Prentice MJ, Hutchinson GR, Taylor-Robinson D: A microbiological study of neonatal conjunctivae and conjunctivitis. Br J Ophthalmol 1977, 61: 601-7.

${ }^{8}$ Pierce JM, Ward ME, Seal DV: Ophthalmia neonatorum in the 1980s: incidence, aetiology and treatment. Br J Ophthalmol 1982, 66: 728-31.

${ }^{9}$ Etches PC, Leahy F, Harris D, Barnes JD: Lysozyme in the tears of newborn babies. Arch Dis Child 1979, 54: 218-21.

${ }^{10}$ Schacter J and Dawson CR: Human Chlamydial Infections. Littleton, Massachussets. PSG Publishing Co Inc 1978 Ch6 111-20.

${ }^{11}$ Editorial. Ophthalmia neonatorium today. Lancet 1984, ii: 1375-6.

12 Editorial. Chlamydial Infections of the Eye. Lancet 1977, ii: 857-8.

${ }^{13}$ Freedman A. et al.: Infection by TRIC agent and other members of the Bedsonia Group; with a note on Reiter's disease. II. Ophthalmia neonatorium due to TRIC agent. Trans Ophthalmol Soc UK 1966, 86: 313-20.

${ }^{14}$ Hobson D, Stefanidi D, Rees E, Tait IA: Effects of chloramphenicol on Chlamydia trachomatis infection in neonatal conjunctivitis and in McCoy cell cultures. J Hyg Camb 1982, 89: 457-66.

${ }^{15}$ Hobson D, Rees E, Viswalingham ND: Chlamydial infections in neonates and older children. $\mathrm{Br} \mathrm{Med}$ Bull 1983; 39: 128-32.

${ }^{16}$ Mallinson H, Roberts C, Waitkins SA, Davidson DC: Ophthalmia Neonatorum Today. Lancet 1985 , i: $350-1$.

${ }^{17}$ Darougar S, Walpita P, Thaker U, Viswalingham ND, Gardner L, McSwiggan DA: Adenovirus serotypes isolated from ocular infections in London. Br J Ophthalmol 1983, 67: 111-4.

${ }^{18}$ Darougar S, Grey RHB, Thaker U, McSwiggan DA: Clinical and epidemiological features of adenovirus keratoconjunctivitis in London. $\mathrm{Br} \mathrm{J}$ Ophthalmol 1983, 67: 1-7.

${ }^{19}$ Schmitz H, Wigand R, Heirich W: Worldwide Epidemiology of Human Adenovines Infections. Am J Epidemiol 1983, 117: 455-66.

${ }^{20}$ Sutton RNP, Pullen-Hazel JM, Blackledge P, Brown EH, Sinclair L, Swift PN: Adenovirus subtype 7; 1971-1974. Lancet 1976, ii: 987-91.

${ }^{21}$ Lipton J, and Patterson A: Epidemic keratoconjunctivitis in Liverpool. J Roy Coll GP 1984, 34: 519-20. 
22 Wishart PK, James C, Wishart MS, Darougar S: Prevalence of acute conjunctivitis caused by chlamydia, adenovirus and herpes simplex virus in an ophthalmic casualty department. $\mathrm{Br} J$ Ophthalmol 1984, 68: 653-5.

${ }^{23}$ Ronnestam R, Persson K, Hannsson H, Renmarker $\mathrm{K}$ : Prevalence of chlamydial eye infection in patients attending an eye clinic, a VD clinic, and in healthy persons. Br J Ophthalmol 1985, 69: 385-8.
${ }^{24}$ Tullo AB, Richmond SJ, Easty DL: The presentation and incidence of paratrachoma in adults. J Hyg Camb 1981, 87: 63-9.

${ }^{25}$ Darougar S, Wishart MJ, Viswalingham ND: Epidemiological and clinical features of primary herpes virus ocular infections. Br J Ophthalmol 1985, 69: 2-6.

${ }^{26}$ Csonka GW, and Coofalik ED: Chlamydial, gonococcal and herpes virus infection in neonates. Postgrad Med J 1977, 53: 592-4. 